\title{
PROSPECTS OF CREATING THE REFLECTIVE TEACHER FOR CONTINUING PROFESSIONAL DEVELOPMENT (CPD)
}

\author{
Yousra Ali Aghanimi1 ${ }^{1}$, Fawzia Mohamed Elwafi², \& Fahima Mohamed Bannur ${ }^{3 *}$ \\ 1,3 University of Tripoli, Tripoli, Libya \\ 2 University of Alhadera, Tripoli, Libya \\ fmohb@yahoo.com*
}

\begin{abstract}
Teacher self-evaluation is an important dimension in the overall evaluation activities in educational programs. However, this dimension is often overlooked and not given its rightful share of importance in the Libyan context. Teacher self-evaluation is neither included in teacher training programs nor is considered a basic requirement from teachers as they develop in their careers. Hence, this research aimed at drawing attention to teacher selfevaluation as an essential tool in continuing professional development. The significance and value of teacher self-evaluation as a core element in continuing professional development requires that self-evaluation proceed with all other forms of evaluation. To support the claim that teacher self-evaluation is a missing element in the area of investigation, the researchers adopted a quantitative study where a questionnaire was administered and a sample of 86 Libyan teachers was chosen randomly from eleven schools. The results of the study showed that while many teachers perform some sort of self-reflection about their teaching, they do not recognize self-evaluation as a basic requirement in developing their career. When the effectiveness of teacher self-evaluation was probed in contrast to external evaluation, most teachers agreed that teacher self-evaluation could play a far more vital role in continuing professional development.
\end{abstract}

Keywords: Continuing Professional Development, External Evaluation, Self-Evaluation

\section{INTRODUCTION}

A teacher is traditionally viewed as someone responsible for transmitting sort of knowledge to learners. Generally speaking, a teacher is seldom viewed as a learner. However, the learning process never stops for teachers especially for those who are eager to be creative in the teaching domain. Development demands constant updating and coping with the new trends in the ever-changing field of education (Kaso et al., 2021). A teacher is indeed a learner; a learner in a vast field whose concern is not only seeking the knowledge of the specialized field but more importantly it is concerned with learning to teach.

Continuous development can be guaranteed by different procedures of which evaluation is a basic requirement. Teacher evaluation is traditionally performed by external bodies in the form of periodic visits in which teachers are observed and judged. However, evaluation can also be internal. This occurs when evaluation is undertaken by the teachers 
themselves or by their peers and students. The Libyan educational programs lack adequate evaluation activities. Evaluation through current inspection performed by external bodies is limited and insufficient for teacher development. Teacher self-evaluation as another supporting source of evaluation is almost non-existent in the Libyan schools and teacher training programs. Recently, teacher self-evaluation attracted scholars' attention where it is considered a valuable part of teachers' professional development.

Self-evaluation refers to the process where teachers collect information about their classroom teaching and classroom management to make judgments about the effectiveness of their performance. It is a form of evaluation undertaken by the teacher for professional development. On basis of these judgments, future decisions and plans are made. Teacher self-evaluation is considered an immediate and practical method for promoting the use of more effective teaching (Bullard, 1998; Kilbourn, 1991; cited in Keller et al. 2005 and Stronge 2005).

Teacher self-evaluation has a fundamental role in the teacher's professional, experience and academic development. First, it can be seen as the main measuring tool for evaluating teachers' efficiency and professionalism. The teacher's monitoring of his or her work, knowledge, skills and attitudes is the foundation on which improvement can proceed. Second, it promotes a self-directed teacher as it is believed by (Wilcox et al. 1998, cited in Koutsolis, 2007) that teachers' self-evaluation will enhance teacher autonomy where teachers become responsible for the continuing improvement of instruction. Raising the awareness of teachers to the importance of self-evaluation in developing their career and making them realize that achieving development should stem first from the teacher's side, would be a basic step towards developing a self-directed teacher. Third, it is a shift towards formative evaluation (process evaluation). Teachers are evaluated for two main purposes described as either formative or summative. The formative evaluation consists of evaluation practices meant to shape, form, or improve teachers' performances. In contrast, summative evaluation aims at providing summary judgments of teachers for purposes such as promotion, employment, rewarding or employment termination. General evaluation practices typically target summative purposes rather than formative purposes. Rea-Dickins \& Germaine (1992:37) state that using observation for promotion purposes is extremely limiting and draws attention to the importance of "...formative value of classroom observation where the feedback from the evaluation will be used to further develop or improve an aspect of classroom or teacher self-development." Formative evaluation does not only depend on outside personnel, but it should also involve teachers, where a more participant-oriented evaluation is significant in raising teachers' awareness and a key feature of the teacher development process. Fourth, it is an aid of following up change and new trends. Change is one main characteristic of the field of education. New visions are constantly introduced with new strategies and equipment. Teachers need to update their knowledge base concerning both knowledge of the subject matter and knowledge of teaching strategies. Teacher selfevaluation could provide the teacher with the chance to measure and compare his or her capacity and resources with the recent trends in education.

External inspection is currently the most common tool for evaluating teachers. However, the limitation of external evaluation systems and the lack of adequate and regular 
communication between inspectors and teachers have weakened the contribution of inspectors in responding to the teachers' need for consultation and improvement. Teachers, apart from some quantitative remarks, do not get detailed feedback about their performance. Therefore, according to Neil \& Morgan ( 2003: 196) “...inspection is summative with judgments made using standardized criteria for accountability purposes", and for (Hopkins et al. 1999 cited in Koutsoulis, 2007:340) “...the occasional character of teacher inspection does not contribute to the improvement of the quality of the education." Therefore, teacher self-evaluation might serve as good means to overcome the shortcomings of a traditional evaluation carried out through external sources. This argument does not imply that external evaluation is to be ignored. The importance of an outside experienced eye that could uncover things that could not be seen by the teachers cannot be dispensed with. Horne \& Pierce (2013) suggest that self-evaluation should come as a step before external evaluation. This step could help in identifying possible areas of focus and provide evidence to assist in the evaluation process. Besides, self-confidence independence, creativity, and self-reliance are all facilitated when self-criticism and self-evaluation are basic and evaluation by others is of secondary importance.

Teacher self-evaluation is often confronted with questions such as: how reliable is personal judgment? How objective is it? Could teachers' ratings of themselves correspond to the inspectors' ratings? Are the criteria of good teaching well known to the teacher? The main criticism of self-evaluation stems from a claim that teachers are not capable of assessing themselves objectively. As a result, it is claimed that teachers tend to under-mark or over-mark themselves when compared with inspectors' evaluation.

Buchanan \& Jackson (1998) and Kagan \& Tippens (1991 cited in Keller et al. 2005) have discussed the value of using self-evaluation techniques which included attention to the accuracy in collecting specific data on one's teaching as well as using this data to make decisions. It was found that initial attempts at self-evaluation do not correspond with external evaluation. Self-evaluation tend to be more positive than supervisors' ratings. However, we must bear in mind that self-evaluation is a complex task that requires the training and support of professional evaluators. Most teacher education programs do not include such activities. The following studies show that intervention programs in selfevaluation lead to more realistic and objective results.

The study that was conducted by Keller et al. (2005) was an attempt to show that when teachers are trained to look for specific data and devise proper techniques to measure a specific behaviour, they might improve their ability to judge themselves. To prove this hypothesis, the researchers experimented on three trainee teachers to examine the effects of a self-evaluation intervention on the instructional behaviour of these teachers. The researchers used video-based teacher self-evaluation. The specific target for evaluation was "using specific social praise in the classroom". In the experiment, the student teachers were asked to measure the amount of praise they use in the classroom before and after an intervention program. The intervention was in the form of giving interns individual training sessions. All three interns immediately increased their use of the targeted behaviour (specific social praise) when the intervention was implemented. 
Wright et al. (2012) conducted an experiment that aimed to show the effect of immediate or delayed video-based teacher self-evaluation on teachers' use of praise. They presented 51 teachers with a self-evaluation package, which included observation skills training, self-monitoring, and goal-setting. The results showed that the evaluation package significantly increased the amount of teachers' general praise and the intervention affected the teachers' performance. Therefore, answering the question of how reliable self-evaluation could be is a matter that is highly dependent on training. For a teacher to possess the ability of self-assessment, the teacher must satisfy a basic background of knowledge or experience that forms the base for further improvement.

As research on Libyan EFL teachers self -evaluation can be considered scarce since most of the conducted research is concerned with other aspects related to the teaching process, the researchers intended to investigate this domain due to its essential role in qualifying teachers and developing their teaching capabilities.

The research specifically seeks to answer two questions. First, does teacher selfevaluation exist in the Libyan education programs? Second, do Libyan teachers use selfevaluation procedures in their teaching to develop their career? The research aims to draw attention to the importance of teacher self-evaluation in continuing the professional development of teachers. It also aims to show that teacher self-evaluation does not constitute a part of the evaluation process in the current Libyan educational program and it is not recognized by both the Libyan schools and teachers as a vital requirement of professional development.

\section{METHODS}

To testify the claim that teacher self-evaluation is neither included in the teacher training program nor is formally recognized by schools and teachers in the Libyan context, the researchers designed a questionnaire that consists of eight questions to probe teachers' views about the study theme. The survey covered 11 schools in the Tajoura area (eastern part of Tripoli) and involved 86 Libyan teachers aged between 22-40 years. They were picked randomly from 5 elementary, 3 preparatory and 3 secondary schools. The teachers were 25 males and 61 females. They were of different specializations (Mathematics, English, History, Biology, Physics, and Physical Education) and different experiences (ranged from beginners to teachers of over 15 years of experience). The questionnaire was piloted to test its validity and reliability before it was used to collect the required data. Quantitative data were collected, classified, organized and then analyzed using the Microsoft Excell program. Moreover, while administering the questionnaire, the researchers had valuable discussions with the teachers who participated in the survey. These discussions provided another source of information that concerned the availability of training courses, relationship with inspectors, criteria of good teaching, availability of adequate resources and student feedback. The content of these discussions is laid out in the discussion below. The results of the questionnaire are listed in tables (1\&2) and figures (1\&2) below. Because the educational system in Tajoura is officially part of the central system in Tripoli, the researchers expect 
that the results might be applied and generalized to many schools in Tripoli as well as Libyan schools.

\section{RESULTS}

Data obtained from the questionnaire are summarized as follows:

Table 1. Teachers' responses about teacher self-evaluation theme(questionnaire items 1-7)

\begin{tabular}{|c|c|c|c|c|c|c|c|c|c|}
\hline \multirow{2}{*}{ Responses } & \multicolumn{2}{|c|}{ Always } & \multicolumn{2}{|c|}{ Sometimes } & \multicolumn{2}{|c|}{ Rarely } & \multicolumn{2}{|c|}{ Never } & \multirow[t]{2}{*}{$\mathrm{NA}^{*}$} \\
\hline & No. & $\%$ & No. & $\%$ & No & $\%$ & No & $\%$ & \\
\hline $\begin{array}{l}\text { Does the school introduce } \\
\text { teachers to self-evaluation } \\
\text { techniques? }\end{array}$ & 13 & 15.1 & 27 & 31.3 & 9 & 10.4 & 37 & 43 & \\
\hline $\begin{array}{l}\text { Do teacher training courses } \\
\text { include sections for self- } \\
\text { evaluation? }\end{array}$ & 5 & 5.8 & 15 & 17.4 & 13 & 15.1 & 51 & 59.3 & 2 \\
\hline $\begin{array}{l}\text { Are high quality teaching criteria } \\
\text { well-known to the teacher? }\end{array}$ & 37 & 43 & 35 & 40.6 & 6 & 6.9 & 4 & 4.6 & 4 \\
\hline $\begin{array}{l}\text { Do you reflect on your } \\
\text { performance after lessons? }\end{array}$ & 66 & 76.7 & 15 & 17.4 & 2 & 2.3 & 3 & 3.4 & \\
\hline $\begin{array}{l}\text { Do you use self-evaluation } \\
\text { procedures periodically? }\end{array}$ & 7 & 8.1 & 28 & 32.5 & 17 & 19.7 & 32 & 37.2 & 2 \\
\hline $\begin{array}{l}\text { Do you ask peers to observe and } \\
\text { evaluate your performance? }\end{array}$ & 10 & 11.6 & 34 & 39.5 & 12 & 13.9 & 30 & 34.8 & \\
\hline $\begin{array}{l}\text { Do you ask your students their } \\
\text { feedback about your } \\
\text { performance? }\end{array}$ & 33 & 38.3 & 31 & 36 & 12 & 13.9 & 10 & 11.6 & \\
\hline
\end{tabular}

*N.A. refers to unanswered questions

Further, teachers' views about questionnaire items 1-7 are presented in figure(1): 


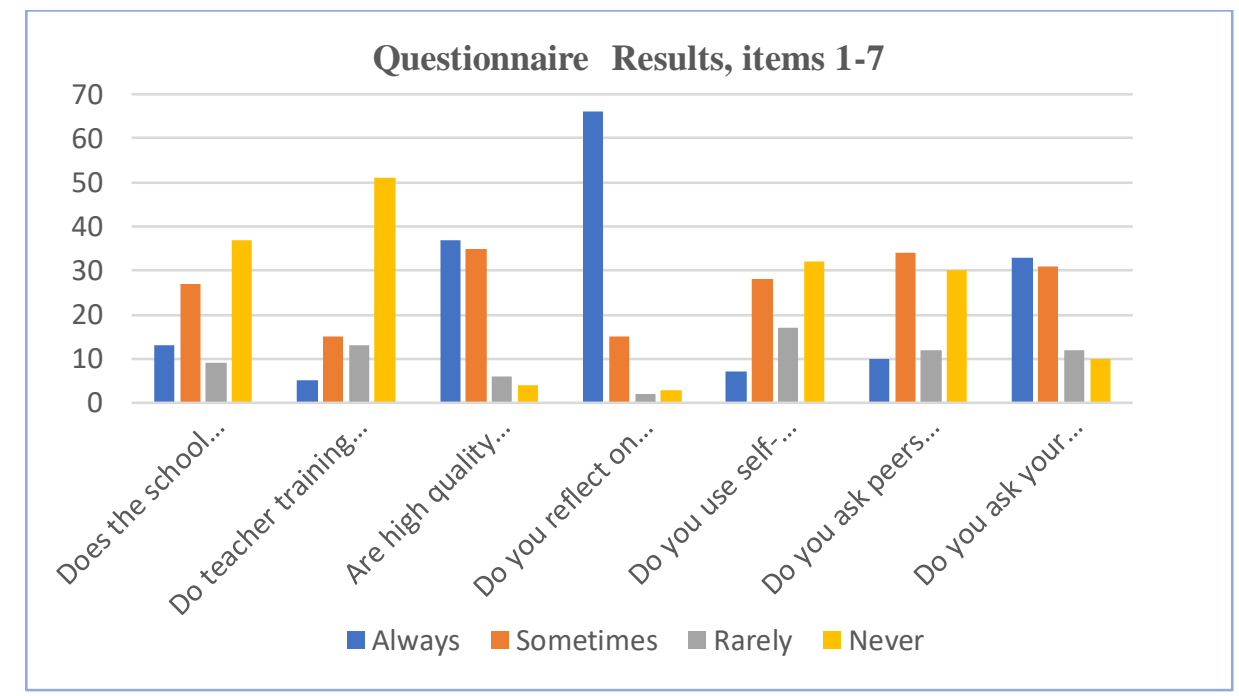

Figure 1. Teachers' responses about teacher self-evaluation (questionnaire items 1-7)

Table 2. Teachers' responses about self-evaluation effectiveness ( questionnaire item 8)

\begin{tabular}{lllllllll}
\hline \multicolumn{1}{c}{ Responses } & \multicolumn{2}{l}{$\begin{array}{l}\text { Strongly } \\
\text { agree }\end{array}$} & Agree & \multicolumn{3}{c}{ disagree } & \multicolumn{2}{c}{$\begin{array}{l}\text { Strongly } \\
\text { disagree }\end{array}$} \\
& No. & $\%$ & No. & $\%$ & No & $\%$ & No & $\%$ \\
\hline $\begin{array}{l}\text { 8. Do you believe self-evaluation is } \\
\text { more effective for teacher } \\
\text { development than inspectors' }\end{array}$ & 67 & 77.9 & 16 & 18.6 & 2 & 2.3 & 1 & 1.1 \\
evaluation? & & & & & & & & \\
\hline
\end{tabular}

Figure 2 displays the percentages of the teachers' views about whether self-evaluation is more effective than inspectors' evaluation. 


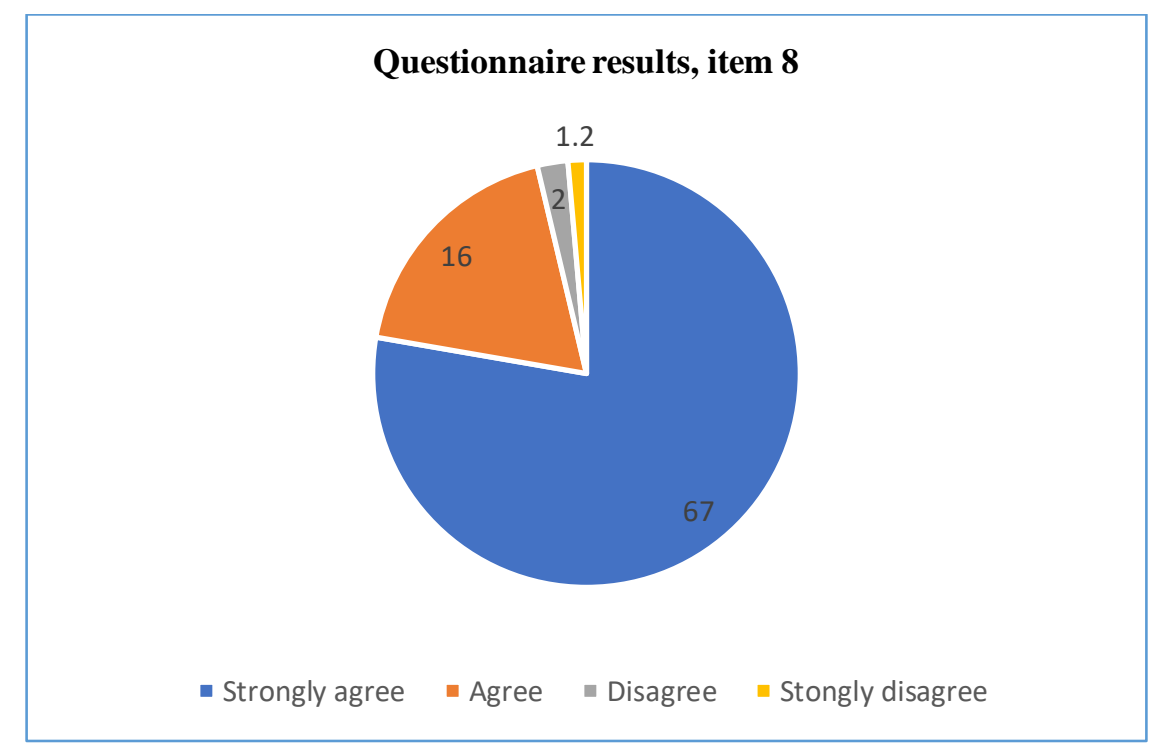

Figure 2. Teachers' perception about self-evaluation effectiveness (questionnaire item 8)

\section{DISCUSSION}

The questionnaire results illustrated in the table (1), (items 1-7) and figure (1), support the research claim that the schools of the area under investigation lack adequate teacher self-evaluation activities. This is shown in the answers to question 1, Does the school introduce teachers to self-evaluation techniques?, where 37 teachers ( $34 \%$ ) say that the school does not introduce the self-evaluation concept altogether so needless to say they further present them with self-evaluation techniques. Some of the teachers, whose answers were "always or sometimes", said that self-evaluation is introduced as an optional activity and was not an obligatory requirement. It is understood that while self-evaluation is desired by some schools, it is often considered marginal. The schools depend entirely on the limited and occasional visits of inspectors which do not respond to the needs of the teachers for development. Therefore, in line with the assertions of Goddard and Emerson (1995), the need to raise the awareness of the school and the teachers of the importance of teacher selfevaluation in creating the autonomous teacher persists.

Teacher self-evaluation, like all the other elements of teaching, needs training. Buchanan \& Jackson (1998) found that initial attempts at self-evaluation do not correspond with objective, external evaluation. However, Keller et al. (2005) assert that intervention training programs could lead to more accurate self-evaluation rates. Therefore, it was necessary to question the participants about the availability of such training programs. Answering question 2, Do teacher training courses include sections for self-evaluation?, 51 teachers (59\%) say that self-evaluation does not constitute a part of any training programs they attend and commented that training programs, in general, are scarce and they do not expect such activity to be included. 
For a teacher to possess the ability of self-assessment, he must satisfy a basic background of knowledge or experience that forms the base for further improvement. On questioning the participants about their knowledge about the criteria of high-quality teaching, question 3, Are high-quality teaching criteria well-known to the teacher?, 37 (43 \%) of the participants say they are aware of these criteria, 35 (40.6\%) say sometimes, and only 4 answered" never". However, we should be cautious of such a high percentage of claimed awareness of high-quality teaching criteria. We must bear in mind that theoretical knowledge does not guarantee that these criteria are applied in actual performance. It is hard to provide evidence that these criteria find their way inside classroom practices given the limited evaluation activities by the school, teacher and inspectors. Those who answered rarely or never, say that they did not have the chance to study teaching methods and strategies. Indeed it seems that a considerable percentage of teachers are graduates of different faculties such as engineering, agriculture, general sciences, who haven't received any training as teachers. Therefore, any teacher self-evaluation training program must include a section about the basic teaching criteria necessary for efficient teaching.

Question 4, Do you reflect on your performance after lessons? is critical for the research because it aims to measure teachers' readability to adopt self-evaluation procedures in their classrooms. The result was 66 teachers (76.7\%) answered that they do some sort of reflection after the end of classes. The discussion with some of the teachers revealed that these reflections do not target specific criteria, but they are general in that they aim to judge whether the teaching process was generally successful or not. However, according to ReaDickins \& Germaine (1992), it is important to be able to determine the cause of success and the cause of failure. Gathering information about the teacher's performance throughout the course and reflecting on them would enable the teachers to understand what contributes to successful teaching and learning. Nevertheless, it suffices at the time being that these reflections are present. If these inclinations are nurtured and developed into actual formal procedures taken by the teachers, this would constitute an important step towards establishing self-evaluation practice in schools.

The aim of question 5, Do you use self-evaluation procedures periodically? is to test whether teachers formally and systematically use self-evaluation procedures. During discussing the questionnaire items, it appeared that many teachers had no idea of what these procedures could be. It was important to present some techniques of self-evaluation such as lesson reports, video-taping, checklists and peer watching. The teachers were very interested to learn about such techniques. The result was 32 teachers (37.2\%) said they never use them and 17 (19.7\%) answered " rarely". However, some of the 28 teachers $(32.5 \%)$ who answered "sometimes", use some sort of report writing about the lesson. Two said they sometimes videotape themselves using their mobile phones. It might be said that even when these techniques are used, they are not used and analyzed systematically nor kept in records such as a teacher's portfolio. More importantly, these techniques are not recognized as a requirement for professional development. The high percentage for those teachers who are not familiar with such techniques raises the urgent need to indulge teachers in training programs that target self-evaluation. 
The aim of question 6, Do you ask peers to observe and evaluate your performance? is to explore teachers' cooperation with their colleagues in this regard. 34 (39.5\%) of teachers say they sometimes do that, but not necessarily attending each other's classes, but mostly in the form of sharing ideas, methods, and materials between experienced teachers and novices. Teachers' preference of dealing with teachers inside the school agrees with Marshall 1998 who stated that working with peers creates a more effective working environment than working with external sources of evaluation.

Question 7, Do you ask your students their feedback about your performance? was met with reserve from teachers thinking that this would mean allowing students to evaluate their teachers. The traditional view that students are not qualified to evaluate the teacher's classroom performance still dominates. It is found that the 33 teachers (38.3\%) who answered "always" and the 31 of them (36\%) who answered "sometimes" believe that asking their students for understanding, for example; "Do you understand?" and "Shall I repeat?" are the main type of feedback they could get from their students. But engaging students in real evaluation concerning the method, material and students' interest is not present. However, recent research findings such as Ronald Ferguson's project (2009) show that learners can recognize effective teaching and they urge policymakers, educators and teachers to seriously consider students feedback. The participants are not aware of the nature of feedback they might obtain from students. Some teachers pointed out that it is difficult to get feedback from elementary school students. Students' feedback is an issue that needs further investigation to determine the type and nature of feedback necessary for the enhancement of the learning process.

Furthermore, teachers were asked about the effectiveness of self-evaluation in question 8: Do you believe self-evaluation is more effective for teacher development than inspectors' evaluation? The responses have been displayed in table (2) and figure (2) above.

This question opened up long discussions with the teachers about the controversial issue of the role of inspectors' evaluation in the development of teachers' performance. The 67 teachers (77.9 \%) who strongly agreed about the importance of their evaluation over inspectors show that the role of inspectors in the development of teachers is almost nonexistent. Teachers have a rather negative attitude towards inspectors. In agreement with Koutsoulis (2007), most participants complained that they do not have enough contact with their inspectors, and when they do, it is often brief and does not meet the teacher's need for consultation. Most participants believe that inspection, as it is functioning today, does not contribute to the teachers' development. Instead, teachers value the role of experienced teachers inside school more than inspectors. Teachers say that, unlike inspectors, the school experienced teachers are present every day and they are familiar with the school environment, conditions, resources and also familiar with the students. These specific conditions enable experienced teachers to pass on more reliable and valid judgments about teachers.

\section{CONCLUSIONS}


Throughout the study, the researchers have emphasized the valuable role of teacher self-evaluation. They have come up with several important findings where there is a shred of evidence that:

1. There is a serious lack of teacher self-evaluation activities in Libyan schools.

2. There are no self-evaluation training programs.

3. The role played by external inspectors in teacher development is inefficient.

4. There is an urgent need to raise awareness about self-evaluation as a tool for teacher continuing development.

5. Teachers favour self-evaluation over inspector evaluation.

6. Teachers prefer dealing with experienced teachers inside schools rather than external personnel from outside the school.

7. The role of the student in the evaluation process is not clear to the teachers and needs further research.

8. The teachers' readiness and eagerness to learn more about self-evaluation procedures is evident.

Teacher self-evaluation enables teachers to discover their points of weaknesses and strengths and subsequently put plans of remedy and improvement. Hence, teacher selfevaluation should form a part of Libyan educational training programs where teachers are introduced to the procedures and steps necessary for implementing self-evaluation in their careers. If teachers succeed in identifying their needs and problems, only then they could benefit from external expertise and only then there would be effective communication between the teacher and other external observers.

It can be concluded that teacher self-evaluation ought not to be marginalized. It should be considered seriously in teacher training programs. There is an urgent need to raise awareness of the significance of self-evaluation as a tool for continuing development. There is a shred of evidence that teachers are eager to learn more about this vital evaluation tool. The study recommends conducting valuable workshops where teachers receive training for using different tools of self-evaluation and improve their capacity to judge themselves and reach objective results about their performance. Self-evaluation should be adopted as a regular and systematic tool of evaluation together with other evaluation tools.

\section{REFERENCES}

Bullard, B. (1998). Teacher Self-evaluation. A paper presented at the annual meeting of the Mid-South Educational Research Association (27th, New Orleans, LA, November 6, 1998). (ERIC Document Reproduction Service No. ED428074).

Buchanan, D. O. U. G. L. A. S., \& Jackson, S. (1998). Supporting self-evaluation in initial teacher education. Scottish Educational Review, 30, 110-124.

Ferguson, R. F. (2009). From the courtroom to the classroom: The shifting landscape of school desegregation. Harvard Education Press. 
Goddard, I. \& Emerson, C. (1995). Appraisal and your School. Oxford. Heinemann

Horne, H., \& Pierce, A. (2013). A practical guide to staff development and appraisal in schools. Routledge.

Hopkins, D., Harris, A., Watling, R., \& Beresford, J. (1999). From inspection to school improvement? Evaluating the accelerated inspection programme in Waltham Forest. British educational research journal, 25(5), 679-690.

Kagan, D. M., \& Tippins, D. J. (1991). Helping student teachers attend to student cues. The Elementary School Journal, 91(4), 343-356.

Kaso, N., Ilham, D., Aswar, N., \& Iksan, M. (2021). The Principal's Leadership: How to Improve the Quality of Teaching and Learning Process in State Junior High School of Luwu. In Jurnal Ad'ministrare (Vol. http://ojs.unm.ac.id/index.php/administrare/index

Koutsoulis, M. (2007). Teacher Evaluation through Inspection. The Enterprise of Education, 337.

Keller, C. L., Brady, M. P., \& Taylor, R. L. (2005). Using self-evaluation to improve studentteacher interns' use of specific praise. Education and training in developmental disabilities, 368-376.

http://daddcec.org/Portals/0/CEC/Autism_Disabilities/Research/Publications/Educa tion_Training_Development_Disabilities/2005v40_Journals/ETDD_200512v40n4p368 -376_Using_Self_Evaluation_Improve_Student_Teacher_Interns_Use.pdf

Neil, P., \& Morgan, C. (2003). Continuing professional development for teachers: From induction to senior management. Psychology Press.

Rea-Dickins, P., \& Germaine, K. (1992). Evaluation. Oxford University Press.

Stronge, J. H. (2005). Evaluating teaching: A guide to current thinking and best practice. Corwin Press.

Wright, M. R., Ellis, D. N., \& Baxter, A. (2012). The effect of immediate or delayed video based teacher self-evaluation on Head Start teachers' use of praise. Journal of Research in Childhood Education 